\section{Microscale Assay for Screening of Inhibitory Activity of Lactobacillus}

BioTechniques 33:1224-1228 (December 2002)

The inhibitory activity of Lactobacillus species has been well documented $(1-5,7,11-13,15)$ and is usually a result of the secretion of secondary metabolites including hydrogen peroxide, organic acids, and peptides (2-5, 11-13,15). Peptides that exhibit an inhibitory effect on any other microorganisms are classified as bacteriocins (5). Bacteriocins have been shown to inhibit a wide range of microorganisms including Gram-positive bacteria $(2,4,5$, $7,11-15)$, Gram-negative bacteria $(2,5$, $9,10)$, and even different bacteria within the same species $(2,5,11)$. The traditional method for screening of bacteriocins is the agar diffusion method $(7,11)$.

The traditional agar diffusion assay is used to screen for direct antagonism of bacteriocin-producing microorganisms against other microorganisms. The assay was first described by Tagg et al. (11) and involves the use of a cell-free supernatant from a Lactobacillus test culture placed into wells on seeded agar plates. The corresponding zones of inhibition are measured in millimeters and are used to quantify the antimicrobial activity. However, the agar diffusion assay depends directly on zone of inhibition to quantify inhibitory activity, and the activity can be influenced by the rate of diffusion of the inhibitory compound through the agar medium $(2,7,9,14,15)$. The agar diffusion assay is not cost effective; each assay requires the use of a large amount of specialized agar plates and sterilized well-forming rings. In addition, the agar diffusion assay requires incubation times of 24,48 , and $72 \mathrm{~h}$ to produce accurate analysis of the inhibitory effect of Lactobacillus (11).

To facilitate the inhibitory screening of Lactobacillus, we developed a microscale optical density assay (MODA) and compared the effectiveness to the agar diffusion method. MODA uses optical density to correlate the secretion of inhibitory compounds with a decrease in indicator cell density. MODA compares the relative decrease in absor- bance between the cultures inoculated with Lactobacillus plantarum (8014; ATCC, Manassas, VA, USA) supernatant and cultures that are inoculated with media.

The MODA examines the effectiveness of secreted inhibitory products from bacterial species based on direct antagonism between these species and target microorganisms in a liquid medium. This removes any effect that the rate of diffusion may have on the results, while only requiring a $24-\mathrm{h}$ incubation time. The MODA also allows for the rapid examination of the effects of proteolytic enzymes, temperature, and $\mathrm{pH}$ on the bacteriocin. These are all common tests used in the screening for the inhibitory activity of Lactobacillus and are important tools to evaluate the antimicrobial activity of Lactobacillus (1-5,7,9,11-13). To test the characteristics of the bacteriocin mentioned above, Lactobacillus supernatant can be treated with several proteases and catalase to rule out hydrogen peroxide. The supernatant can also be adjusted with $1 \mathrm{M}$ $\mathrm{HCl}$ or $1 \mathrm{M} \mathrm{NaOH}$ to examine the effect of $\mathrm{pH}$ and/or dialyzed against a standard buffer ( $\mathrm{pH} 7.8$ ) to rule out the effect of organic acids present only in Modified Rogosa Broth (MRS) (BD Biosciences, San Jose, CA, USA) used to grow L. plantarum that might not be present in normal MRS. Finally, the supernatant can be heated to various temperatures to examine the effect of heat. This versatility allows the MODA to be used as a rapid method to distinguish between bacteriocins and bacteriocinlike factors, which may not be proteins. The result is a rapid and quantifiable analysis of the antimicrobial action of the bacteriocin-producing species, which is helpful when screening either a large number of target microorganisms or a large number of bacteriocinproducing species, or both.

To perform either the agar diffusion assay or MODA, the following culture conditions were used. L. plantarum cultures are grown overnight in MRS at $25^{\circ} \mathrm{C}$ with shaking. Sterile cell-free supernatant was achieved by growing overnight cultures followed by centrifugation at $6500 \times g$ for $5 \mathrm{~min}$. The supernatant is decanted and filtered through a $0.2-\mu \mathrm{m}$ low-protein binding syringe filter (Millipore, Bedford, MA, USA). The inhibitory test cultures (Table 1) are all grown overnight in Nutrient Broth (BD Biosciences) at $37^{\circ} \mathrm{C}$ with shaking. The cultures are then diluted 1:1000 in Nutrient Broth. This dilution was selected because it was the first dilution in which an $\mathrm{OD}_{600}<2.00$ was measured before running the protocols below.

The well diffusion assay is carried out following the protocol described by Tagg et al. (11). To $25 \mathrm{~mL}$ liquid Nutrient agar (BD Biosciences), tempered to $45^{\circ} \mathrm{C}-48^{\circ} \mathrm{C}, 1 \mathrm{~mL}$ diluted test culture $(1: 1000)$ is added. The inoculated agar is then poured onto petri dishes and allowed to solidify. Using a sterilized 10$\mathrm{mm}$ cork borer, wells are cut into the center of the plates, to which $250 \mu \mathrm{L}$ Lactobacillus supernatant are added; to a second plate, $250 \mu \mathrm{L}$ MRS ( $\mathrm{pH} 4.8$ ) are added to serve as a negative control. The plates are then incubated for 24, 48 , and $72 \mathrm{~h}$, with the relative zones of inhibition measured at each time point.

The MODA involves the addition of $100 \mu \mathrm{L}$ diluted test cultures to a well of a 96-well cell culture plate (Corning, Acton, MA, USA). This is done in four separate wells, one to serve as a negative control (no supernatant or media), two to serve as test wells (supernatant, duplicate), and one additional negative control (media). To the test wells, 15 $\mu \mathrm{L}$ cell-free $L$. plantarum supernatant are added; to the media test well, $15 \mu \mathrm{L}$ MRS adjusted to $\mathrm{pH} 4.8$ (the $\mathrm{pH}$ of the cell-free supernatant) are added; to the final well only, diluted test culture is added (no supernatant). The 96-well plate is then covered with a sterile lid and incubated at $37^{\circ} \mathrm{C}$ for $24 \mathrm{~h}$. After incubation, the plate is read on a Multiskan MCC/340 microplate reader (Labsystems, Fisher Scientific, Pittsburgh, PA, USA) at a wavelength of $600 \mathrm{~nm}$ to measure optical density, which can be correlated to cell density.

Table 1 shows the measured inhibitory activity of $L$. plantarum using the MODA. The L. plantarum supernatant showed a strong ability to inhibit all test cultures examined (Table 1). The observations that show that the L. plantarum supernatant inhibited both Gram-positive and Gram-negative microorganisms are interesting. Most studies of antimicrobial properties of Lactobacillus show them to be more inhibitory to closely related species (i.e., Gram-positives) 
Table 1. MODA of $L$. plantarum Supernatant

\begin{tabular}{|c|c|c|c|c|c|c|c|c|c|c|}
\hline \multirow[b]{2}{*}{ Test Sample } & \multicolumn{10}{|c|}{$\begin{array}{c}\text { Absorbance }\left(A_{600}\right) \\
\text { Test Cultures }{ }^{*}\end{array}$} \\
\hline & SA & EC & LI & PA & SE & ML & SM & SF & ST & $\mathrm{BC}$ \\
\hline Control (No Supernatant) & 0.993 & 0.393 & 0.385 & 0.350 & 0.382 & 0.409 & 0.489 & 0.215 & 0.502 & 0.356 \\
\hline Control (MRS) & 0.955 & 0.375 & 0.379 & 0.347 & 0.391 & 0.401 & 0.475 & 0.222 & 0.511 & 0.364 \\
\hline $15 \mu \mathrm{L}$ spent supernatant & 0.112 & 0.032 & 0.013 & 0.011 & 0.053 & 0.015 & 0.075 & 0.013 & 0.034 & 0.040 \\
\hline
\end{tabular}

Table 2. Well Diffusion Assay of L. plantarum Supernatant

\begin{tabular}{|c|c|c|c|c|c|c|c|c|c|c|}
\hline \multirow[b]{2}{*}{ Time (h) } & \multicolumn{10}{|c|}{$\begin{array}{c}\text { Zone of Inhibition (mm) } \\
\text { Test Cultures* }\end{array}$} \\
\hline & SA & EC & LI & PA & SE & ML & SM & SF & ST & BC \\
\hline 24 & 9 & 13 & 14 & 12 & 11 & 15 & 8 & 12 & 11 & 7 \\
\hline 48 & 10 & 14 & 14 & 13 & 12 & 15 & 10 & 12 & 12 & 8 \\
\hline 72 & 12 & 14 & 14 & 15 & 12 & 15 & 10 & 12 & 13 & 10 \\
\hline
\end{tabular}

(2-6,11-15). The L. plantarum bacteriocin in this study has an equal effect on both Gram-positive and Gram-negative organisms (Tables 1 and 2). This broad inhibitory spectrum of Lactobacillus, although rare, has been shown by other investigators $(2,9,10)$, all of whom showed bacteriocins to be effective against Gram-negative species. It should be noted that the inhibitory compound in this study is being referred to as a bacteriocin, since the compound was susceptible to digestion with proteases as well as both heat and $\mathrm{pH}$ denaturation. In addition, the compound retained antimicrobial activity following dialysis against a buffer, ruling out organic acid as the inhibitory compound. Finally, activity was not lost upon treatment with catalase, suggesting that the inhibition was not due to the presence of hydrogen peroxide (results not shown).

The inhibitory activity identified using the MODA strongly corresponds with the results achieved by the agar diffusion assay (Table 2); it should be noted that the MRS control on the well diffusion assay had no measurable zones of inhibition (data not shown). Al- though this report only shows data from one set of experiments, the MODA has been tested several times with $L$. plantarum, and studies currently underway show its validity with other bacteriocinproducing microorganisms including other Lactobacillus and Bacillus subtilis. These findings lend support to the effectiveness of the MODA as a rapid and cost-effective screening technique and reinforce the observation that $L$. plantarum is able to inhibit a broad range of other microbes. The MODA reduces the analysis time to $24 \mathrm{~h}$ and requires much less setup and preparation, making it ideal for the rapid screening of inhibitory action of the bacteriocin on several target species or the bacteriocin production in various bacterial species (4). The correlation between the traditional agar diffusion assay and the microscale assay provides support for its use as a rapid screening technique for inhibitory activity of Lactobacillus. It should be noted that similar methods of examining antimicrobial activity of other compounds are currently being used in other fields, including the microbroth dilution method $(1,4,8,9)$. In conclu- sion, this study provides validation for the use of the MODA as a rapid and cost-effective alternative to the traditional agar diffusion assay used for the examination of bacteriocin activity.

\section{REFERENCES}

1.Daeschel, M. 1992. Procedures to detect antimicrobial activities of microorganisms, p. 58-80. In B. Ray and M. Daeschel (Eds.), Food Bioperservatives of Microbial Origin. CRC Press, Boca Raton, FL.

2.Klaenhammer, T.R. 1988. Bacteriocins of lactic acid bacteria. Biochimie 70:337-349.

3.Messi, P., M. Bondi, C. Sabia, R. Battini, and G. Manicardi. 2001. Detection and preliminary characterization of a bacteriocin (plantaricin 35d) produced by a Lactobacillus plantarum strain. Int. J. Food Microbiol. 64:193-198.

4.Piddock, L.J.V. 1990. Techniques used for the determination of antimicrobial resistance and sensitivity in bacteria. J. Appl. Bacteriol. 68:307-318

5.Rammelsberg, M. and R. Radler. 1990. Antibacterial Peptides of Lactobacillus species. J. Appl. Bacteriol. 69:177-184.

6.Ray, B. 1992. Bacteriocins of starter culture bacteria as food bioperservatives: an overview, p. 177-205. In B. Ray and M. Daeschel (Eds.), Food Bioperservatives of Microbial Origin. CRC Press, Boca Raton, FL. 
7.Richardson, H., A.H. Emslie-Smith, and B.W. Senior. 1968. Agar diffusion method for the assay of colicins. Appl. Microbiol. 16:1768-1774

8.Sahin, G., E. Palaska, M. Ekizoglu, and M. Ozalp. 2002. Synthesis and antimicrobial activity of some 1,3,4-oxadiazole derivatives. Farmaco. 57:539-542.

9.Schumacher, U.K. 1997. Comparison of the Etest and a microbroth dilution system (Sceptor) to a reference agar dilution method for susceptibility testing of Bilophila wadsworthia. Clin. Microbiol. Infect. 3:246-249.

10.Simoes, J.A., A. Aroutcheva, I. Heimer, S. Shott, and S. Faro. 2001. Bacteriocin susceptibility of Gardnerella vaginalis and its relationship to biotype, genotype, and metronidazole susceptibility. Am. J. Obstet. Gynecol. 185:1186-1190.

11.Tagg, J.R., A.S. Dajani, and L.W. Wannamaker. 1976. Bacteriocins of Gram-positive bacteria. Bateriol. Rev. 40:722-756.

12.ten Brink, B., M. Minekus, J.M. van der Vossen, R.J. Leer, and J.H. Veld. 1994. Antimicrobial activity of lactobacilli: preliminary characterization and optimization of production of acidocin B, a novel bacteriocin produced by Lactobacillus acidophilus. J. Appl. Bacteriol. 77:140-148.

13.van Reenen, C.A., L.M.T. Dicks, and M.L.Chikindas. 1998. Isolation, purification and partial characterization of plantaricin 423, a bacteriocin produced by Lactobacillus plantarum. J. Appl. Microbiol. 84:1131-1137.

14.Wolf, C.E. and W.R. Gibbons. 1996. Improved method for quantification of the bacteriocin Nisin. J. Appl. Bacteriol. 80:453-457.

15.Yildirim, Z., Y.K. Avar, and M. Yildirim. 2002. Factors affecting the adsorption of buchnericin LB, a bacteriocin produced by Lactobacillus buchneri. Microbiol. Res. 157:103-107.

This research was supported in part by a Pennsylvania State University, Berks-Lehigh Valley College research and development grant (T.H.M. and H.G.) and by the Department of Food Science, Pennsylvania State University (University Park, PA, USA) (H.G.). Address correspondence to Dr. Tami H. Mysliwiec, The Pennsylvania State University, Berks-Lehigh Valley College, Tulpehocken Road, P.O. Box 7009, Reading, PA 19610,USA.e-mail:thm2@psu.edu

Received 28 May 2002; accepted 23 September 2002.

\section{Bradley W. Lash, Hassan Gourama, and Tami \\ H. Mysliwiec \\ The Pennsylvania State \\ University \\ Berks - Lehigh Valley College \\ Reading, PA, USA}

\section{High-Quality Genomic DNA from Human \\ Whole Blood and Mononuclear Cells}

BioTechniques 33:1228-1230 (December 2002)

The development of efficient and cost-effective technologies for DNA extraction will become of paramount importance considering the thousands of patients and control samples that eventually will be analyzed to identify disease- causing genes and for new drug targets. Moreover, genetic testing for early detection of viral genomes and bacterial contamination of donors' blood is also being universally implemented to assure the greatest safety of blood products and to decrease transfusion risks.

Human genomic DNA isolation by classical protocols has always been a tedious, laborious, and time-consuming procedure involving protease digestion, organic solvent extraction, alcohol precipitation, and centrifugation (12). This multi-step method is largely unsuitable for high-throughput screening. Recent-

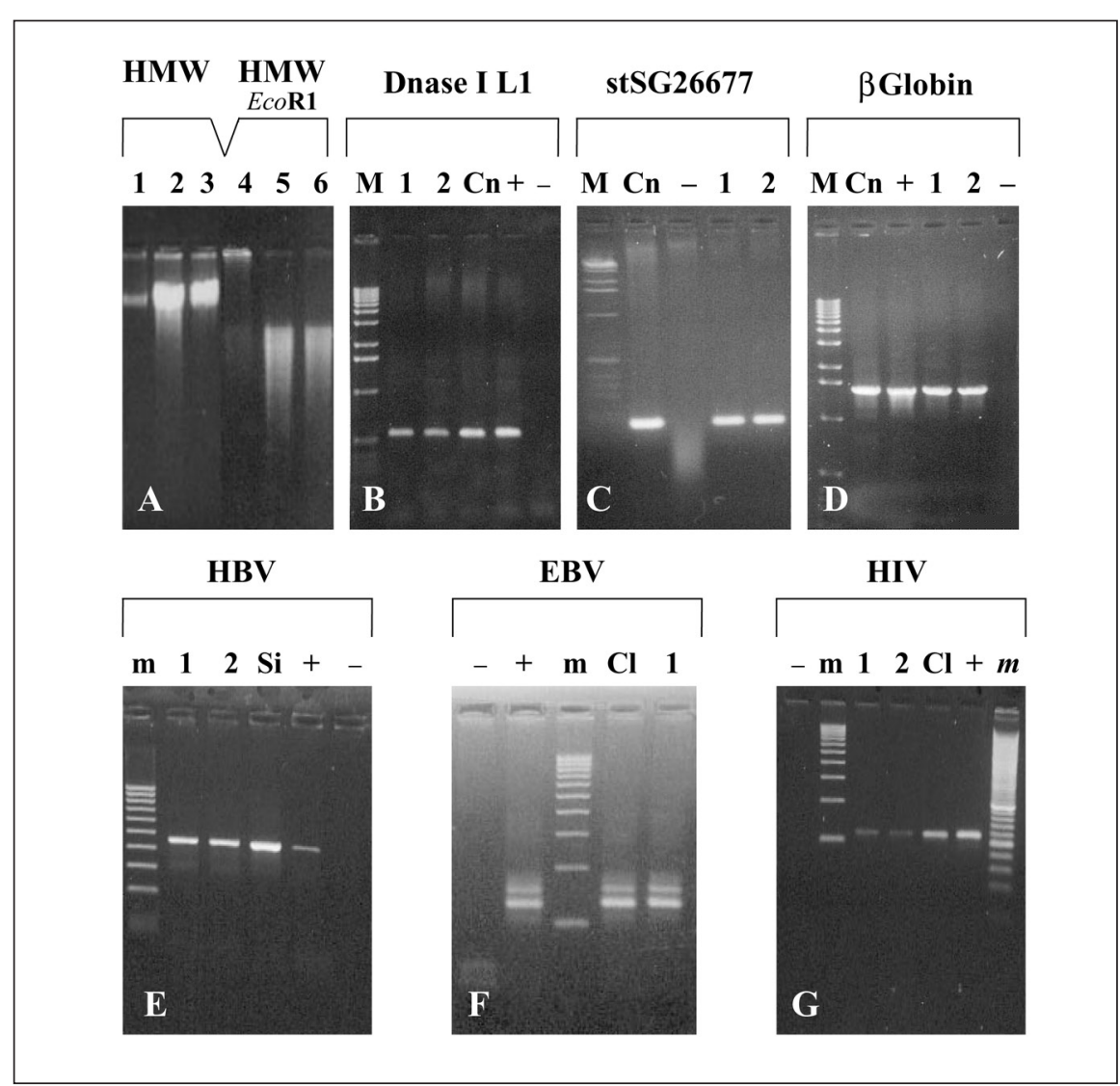

Figure 1. Purification, enzymatic treatment, and PCR amplification of human and viral DNA. (A) High molecular weight (HMW) DNA extracted from human mononuclear cells with a commercially available kit (lane 1) and with the silica-based method (lanes 2 and 3); the same DNA digested with EcoRI (lanes 4, 5, and 6). Equal amount of DNA was loaded on a $0.9 \%$ agarose gel. (B-G) DNA extracted from mononuclear cells by the silica-based method and amplified with DNase I L1-specific primers (panel B, lane 2; expected fragment size, 566 bp); stSG26677-specific primers (panel C, lanes 1 and 2; expected fragment size, $189 \mathrm{bp}$ ); $\beta$-globin gene-specific primers (panel D, lanes 1 and 2; expected fragment size, 1520 bp). Genomic DNA purified with phenol:chloroform (panel B, C, and D, lanes Cn) or with commercially available kits (panel B, lane 1) and DNA plasmids bearing target amplification sequences (panels B and D, lane + ) were used as positive controls. For viral DNA detection, the target amplification sequences were: HIV proviral DNA (HIV; panel G, lanes 1 and 2; expected fragment size, 115 bp); EBV DNA (EBV; panel F, lane 1; expected fragment size, $129 \mathrm{bp}$; upper band is a nonspecific PCR product); HBV DNA (HBV; panel E, lanes 1 and 2; expected fragment size, $452 \mathrm{bp}$ ). Commercially available kits for viral DNA extraction and detection (Sigma and Clonit, respectively, lanes Si and $\mathrm{Cl}$ ) and DNA plasmids bearing target amplification sequences (lanes + ) were used as positive controls. M, 1-kb ladder; m, 100-bp ladder; $m, 20-100$ bp ladder; -, negative control. 